OnLine Journal of Biological Sciences 10 (2): 54-59, 2010

ISSN 1608-4217

(C) 2010 Science Publications

\title{
The Relationship between Serum Cotinine Levels and Periodontal Status
}

\author{
${ }^{1}$ Fouad Hussain AL-Bayaty, ${ }^{2}$ Noor Adinar Baharuddin and ${ }^{3}$ Mahmood Ameen Abdulla \\ ${ }^{1}$ Department of Restorative Dentistry, Faculty of Dentistry, \\ University Technology MARA, Shah Alam Selangor, Malaysia \\ ${ }^{2}$ Department of Oral Pathology, Oral Medicine and Periodontology, \\ Faculty of Dentistry, University of Malaya, Malaysia \\ ${ }^{3}$ Department of Molecular Medicine, Faculty of Medicine, \\ University of Malaya, Malaysia
}

\begin{abstract}
Problem statement: Smoking plays a significant role in the development of periodontal disease. Quantitative relation between smoking and increased severity of periodontal disease, by means of biochemical marker has not been described in Malaysian population. The present study was designed to apply serum cotinine measurement as a quantitative method to evaluate smoking levels in Malaysian patients and to correlate these levels with the severity of periodontal disease. Approach: The study group consisted of 80 healthy individuals (20-64) year, Current Smokers 26, Non Smokers 27 and Former Smokers 27. The subjects were then asked to complete a questionnaire including the demographic, socioeconomic status, medical history and history of cigarette smoking. The periodontal variables recorded were amount of Visible Plaque score, gingival bleeding Index and community periodontal index. Samples of blood " $10 \mathrm{~mL}$ " were obtained in vacutainer tubes containing EDTA for quantitative analysis of serum levels of cotinine. The serum samples were analyzed for cotinine content by means of a competitive-inhibition ELISA technique. Results: Current smokers represent the highest mean cotinine serum level, $95.5 \mathrm{ng} \mathrm{mL} \mathrm{m}^{-1}$, compared to former smokers, $35.5 \mathrm{ng} \mathrm{mL} L^{-1}$ and non smokers, $22.9 \mathrm{ng} \mathrm{mL}^{-1}$. The mean serum cotinine level in periodontally healthy patient showed the highest cotinine level $\left(84 \mathrm{ng} \mathrm{mL}^{-1}\right)$ followed by the gingivitis patients $\left(68 \mathrm{ng} \mathrm{mL}^{-1}\right)$ and $\left(50 \mathrm{ng} \mathrm{mL}^{-1}\right)$ for periodontitis patients. Conclusion: The present observations clearly indicate an association between smoking, periodontal disease clinical parameters "plaque, gingival bleeding scores" and cotinine serum levels in current smokers. Cotinine serum levels doesn't affected by the existence or the severity of periodontal disease.
\end{abstract}

Key words: Cotinine, smoking, periodontal disease

\section{INTRODUCTION}

For many years, cigarette and tobacco use have been the subject of numerous studies (Rivera-Hidalgo, 1986; Genco, 1996). To date, tobacco use continues to be a primary cause of preventable death worldwide.

According to the Global Youth Tobacco Survey by US Center for Disease Control and Prevention, there are 1.2 billion smokers worldwide and $14 \%$ of them are young (National Centre for Health Statistics, 1996). In Malaysia, the prevalence of smoking among young adults has increased from $22 \%$ in 1985 to $28 \%$ in the year 2000. Similarly, the prevalence of smoking among adolescents has increased from $1 \%$ in 1985 to $8 \%$ in 2000.
Interestingly, there have been reports on the decline of smokers among the adult population. Concurrently, an increase among adolescents who smoke was observed (Garfinkel, 1997). The changes that took place whereby more young people adopting smoking lifestyles has probably resulted from the campaign by the cigarette companies that "normalize" the smoking habits. This change in the trend of smoking prevalence worldwide means that in the future people would suffer from chronic illnesses at a younger age and this would represent a public health problem.

The relationship between smoking and Acute Necrotizing Ulcerative Gingivitis was first discovered by Pindborg (1949). However, for other forms of periodontal disease, the prevailing thought for many

Correspondence Anther: Fouad Hussain AL-Bayaty, Department of Restorative Dentistry, Faculty of Dentistry,

University Technology MARA, Shah Alam Selangor, Malaysia

Tel: 00603-55435818 Fax: 00603-55435803 
years was that if smokers did have more periodontal disease, it was due to differences in levels of plaque and calculus.

However, epidemiological studies in the 1980s and 1990s continued to demonstrate the association between chronic inflammatory periodontal disease and smoking. The 1st National Health and Nutritional Examination Survey demonstrated that the association remained even after co-founding factors such as age, gender and socio-economic status is controlled. It was reported that though current smokers had higher levels of plaque and calculus, they still had greater periodontal destruction than former or never smokers (Ismail et al., 1983).

The 3rd national health and nutritional examination survey concluded that approximately 50\% of periodontitis cases were attributed to either current $(41.9 \%)$ or former smokers $(10.9 \%)$. It was also concluded that current smokers were four times more likely to have periodontitis as never smokers. In addition, former smokers were 1.68 times more likely to suffer from periodontitis (Tomar and Asma, 2000). Horning et al. (1992) reported an association between smoking and advanced periodontitis. This is consistent with the hypothesis that smoking has a cumulative effect on periodontal health i.e., the more a patient smokes, the greater the degree of chronic inflammatory periodontal disease.

There are a number of theories as to why smokers have more periodontal disease than non-smokers, involving both bacterial aspect and host response (Razali et al., 2005). Initially it was thought that smokers may have higher plaque than non smokers, which may be accounted for by poorer levels of oral hygiene than higher rates of supragingival plaque growth (Bergstrom et al., 2000; Bergstrom, 1989). Later, numerous studies of the potential mechanisms whereby smoking tobacco may predispose to periodontal disease have been conducted. Smoking has profound effects on the immune and inflammatory system revised by Barbour et al. (1997). Smoking has adverse effects on fibroblast function (Raulin et al., 1988), chemotaxis and phagocytosis by neutrophils (Kenney et al., 1997) and immunoglobulin production (Holt, 1987; Johnson et al., 1990).

Self-reported history on smoking is routinely used to classify smokers and non-smokers as well as determine the prevalence of smoking in epidemiological studies, however, quantitation of the level of smoking based on self reports may be at times unreliable.

Nicotine content of cigarette varies from brand to brand and smoking patterns may vary among individuals, which may explain the nicotine level differences. Nicotine, one of the most important components of tobacco, has a plasma life of approximately $30 \mathrm{~min}$ (Machacek and Jiang, 1986) and it is quickly converted to its metabolite, cotinine. The latter has been used as a biomarker of tobacco use (Cuff et al., 1989; Watts et al., 1990) and its plasma half-life is longer than that of nicotine, ranging from 10-30 h (Benowitz et al., 1983).

Cotinine levels may represent an alternative measure of tobacco exposure to complement. Due to health risks associated with tobacco exposure, analysis of biomarkers of tobacco research has increased. Cotinine is the preferred serum biomarker for tobacco exposure. Cotinine levels can be an objective, reliable and quantitative method analytical tool to evaluate the role of smoking in periodontal disease and in passive smoking.

Data from the 1988-1991 National Health and Nutritional Examination Survey found that $87.9 \%$ of non smokers had detectable concentrations of serum cotinine (Pirkle et al., 1996).

Based on this literature review, it is becoming more evident that smoking plays a significant role in the development of periodontal disease. However, a quantitative relation between smoking and increased severity of periodontal disease, by means of biochemical marker has not been described in Malaysian population. It was thus the scope of this study to apply serum cotinine measurement as a quantitative method to evaluate smoking levels in Malaysian patients and to correlate these levels with the severity of periodontal disease.

\section{MATERIALS AND METHODS}

The subjects recruited were either patients or those accompanying patients to the Primary Care Unit (PCU), Faculty of Dentistry, University of Malaya. The study group consisted of 80 healthy individuals, Current Smokers 26, Non Smokers 27 and Former Smokers 27. They were all free of any systemic diseases and they were not using any medication. Their mean age was $40.4 \pm 12.0$ (20-64) year. All participants were carefully informed about the aims of the investigation and they were free to withdraw at any time during the course of the investigation. All subjects were required to sign a written consent form prior to commencement of the study. The study was approved by the Ethical Committee of the University of Malaya (DF OP0701/0003(L).

The subjects were then asked to complete a questionnaire including the demographic, 
socioeconomic status, medical history and history of cigarette smoking. The questionnaire was filled out independent of the clinical examination. The smoking exposure to the individual was expressed in terms of consumption, i.e., the numbers of cigarettes consumed per day, duration, the number of years of smoking. Assessment of smoking status performed according to the criteria established by the Centre for the Disease Control and Prevention (CDC). Current smokers were defined as those who had smoked over 100 cigarettes over a lifetime and were smokers at the time of interview. Former smokers were those who smoked over 100 cigarettes in a lifetime but not currently smokers, while never smokers were those who did not smoke over 100 cigarettes in a lifetime.

All subjects were examined at the clinic of the department of Periodontology Faculty of Dentistry, University of Malaya. The periodontal variables recorded were amount of Visible Plaque score (Ainamo and Bay, 1975), gingival bleeding Index (Ainamo and Bay, 1975) and community periodontal index (Ainamo et al., 1982). Samples of blood "10 mL" were obtained in vacutainer tubes containing EDTA for quantitative analysis of serum levels of cotinine. All blood samples were centrifuged serum aspirated in new tubes and conserved in a deep freezer under $-20^{\circ} \mathrm{C}$ until subjected to laboratory analysis. The serum samples were analyzed for cotinine content by means of a competitive- inhibition ELISA technique. Statistical significance of differences between means was tested with the student t-test. The following significance levels were used $\mathrm{p}<0.05,0.01,0.002$ and $\mathrm{p}>0.001$.

\section{RESULTS}

A total of eighty patients were examined. Of these, $26(32.5 \%)$ were current smokers, 27 (33.75\%) were non smokers and $27(33.75 \%)$ were former smokers. Table 1 displays the groups by age and smoking.

The frequency distribution of current smokers and former smokers by cigarette consumption and smoking duration appears in Table 2 and 3, respectively. A slightly higher proportion of former smokers (44\%) used to smoke less than 10 cigarettes per day than current smokers $(42 \%)$. While a higher percentage of former smokers $(44 \%)$ used to smoke more than 15 cigarettes per day than current smokers (27\%).The mean duration was 21 years and 15 years respectively.

Table 4 showed that current smokers and former smokers have a significantly higher mean gingival bleeding index compared to non smokers. There is however, no significant difference in mean plaque index between smokers, former smokers and non smokers. Figure 1 demonstrates cigarette consumption per day for both former smokers and current smokers; it was 20.7 and 15.6 respectively.

Figure 2 displays the mean cotinine serum level in the three groups. Current smokers represent the highest mean, $95.5 \mathrm{ng} \mathrm{mL} \mathrm{mL}^{-1}$, compared to former smokers, $35.5 \mathrm{ng} \mathrm{mL}^{-1}$ and non smokers, $22.9 \mathrm{ng} \mathrm{mL}^{-1}$. In this study, Community Periodontal Index (CPI) was used as a measurement of assessing periodontal status, the sample was divided into three groups healthy, patients with gingivitis and patients who had periodontitis. Table 5 shows the mean serum cotinine level in these groups, periodontally healthy patient showed the highest cotinine level (84 $\mathrm{ng} \mathrm{mL}^{-1}$ ) followed by the gingivitis patients $\left(68\right.$ and $50 \mathrm{ng} \mathrm{mL}^{-1}$ ) for periodontitis patients.

Table 1: Breakdown of the sample by group according to age and smoking status

\begin{tabular}{lllll}
\hline & Age & & & \\
& n* & mean & SD & Range \\
\hline Current smokers & 26 & 36.0 & 11.1 & $20-54$ \\
Former smokers & 27 & 45.1 & 10.6 & $22-55$ \\
Non smokers & 27 & 40.3 & 12.8 & $20-64$ \\
\hline $\mathrm{n}^{*}:$ Number of subject & & & &
\end{tabular}

Table 2: Frequency distribution of smokers according to cigarette consumption/day

\begin{tabular}{|c|c|c|c|c|c|c|c|c|}
\hline & \multicolumn{8}{|c|}{ Consumption/day } \\
\hline & \multicolumn{2}{|c|}{$\leq 10$} & \multicolumn{2}{|c|}{$11-15$} & \multicolumn{2}{|c|}{$>15$} & \multicolumn{2}{|c|}{ Total } \\
\hline & $\mathrm{n}$ & $(\%)$ & $\mathrm{n}$ & $(\%)$ & $\mathrm{n}$ & $(\%)$ & $\mathrm{n}$ & $(\%)$ \\
\hline Current smokers & 11 & $(42)$ & 8 & (31) & 7 & (27) & 26 & $(100)$ \\
\hline Former smokers & 12 & (44) & 3 & (11) & 12 & (44) & 27 & (100) \\
\hline
\end{tabular}

Table 3: Frequency distribution of smokers according to smoking duration

\begin{tabular}{|c|c|c|c|c|c|c|c|c|c|c|c|}
\hline & \multicolumn{11}{|c|}{ Smoking duration (years) } \\
\hline & \multicolumn{2}{|c|}{$\leq 10$} & \multicolumn{2}{|c|}{$11-15$} & \multicolumn{2}{|c|}{$16-20$} & \multicolumn{2}{|c|}{$>20$} & \multicolumn{2}{|c|}{ Total } & \multirow{2}{*}{$\begin{array}{l}\text { Mean } \\
\text { duration }\end{array}$} \\
\hline & $\mathrm{n}$ & $(\%)$ & $\mathrm{n}$ & $(\%)$ & $\mathrm{n}$ & $(\%)$ & $\mathrm{n}$ & $(\%)$ & $\mathrm{n}$ & $(\%)$ & \\
\hline Current smokers & 12 & (46) & 3 & (12) & 6 & (23) & 5 & (19) & 26 & $(100)$ & 15 \\
\hline Former smokers & 6 & (22) & 3 & (11) & 6 & (22) & 12 & (44) & 27 & $(100)$ & 21 \\
\hline
\end{tabular}


OnLine J. Biol. Sci., 10 (2): 54-59, 2010

Table 4: Plaque and gingival bleeding score for current, former and non-smokers

\begin{tabular}{|c|c|c|c|c|c|c|c|c|c|}
\hline & \multicolumn{2}{|c|}{ Current smokers } & \multicolumn{2}{|c|}{ Former smokers } & \multicolumn{2}{|c|}{ Non-smokers } & \multirow[b]{2}{*}{$\mathrm{P}$} & & \\
\hline & Mean & (SD) & Mean & (SD) & Mean & (SD) & & & \\
\hline Plaque & 52 & (11.6) & 49 & (21.5) & 50 & (19.8) & 1.0 & 1.0 & 1.0 \\
\hline Gingival bleeding & 27 & (13.9) & 44 & (22.3) & 25 & (19.0) & $0.002^{*}$ & 1.0 & $0.001^{*}$ \\
\hline
\end{tabular}

All values are expressed as mean and standard deviation; means with ${ }^{*}$ : superscript are significantly different

Table 5: Mean Serum cotinine level according to periodontal status

\begin{tabular}{llll}
\hline & Serum cotinine level & \\
& - & & \\
& Mean & (SD) & P \\
\hline Healthy & 84 & $(51.6)$ & - \\
Gingivitis & 68 & $(52.3)$ & 0.256 \\
Periodontitis & 50 & $(55.8)$ & 0.058 \\
\hline
\end{tabular}

All values are expressed as mean and standard deviation; means with *: superscript are significantly different compared to healthy group

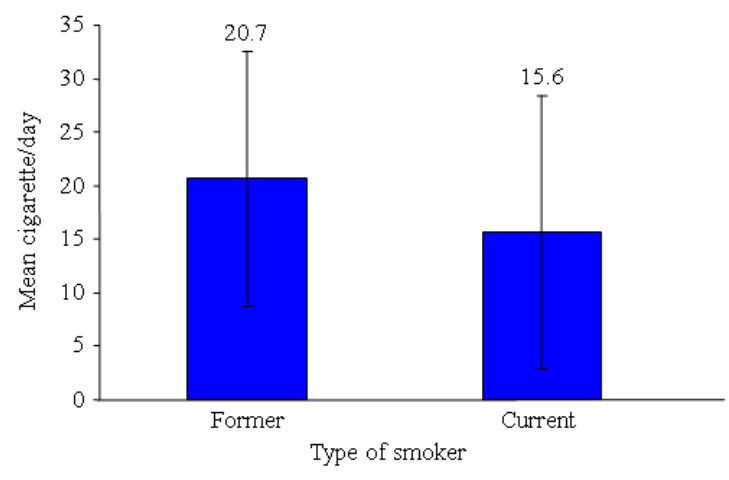

Fig. 1: Mean reported number of cigarettes smoked per day

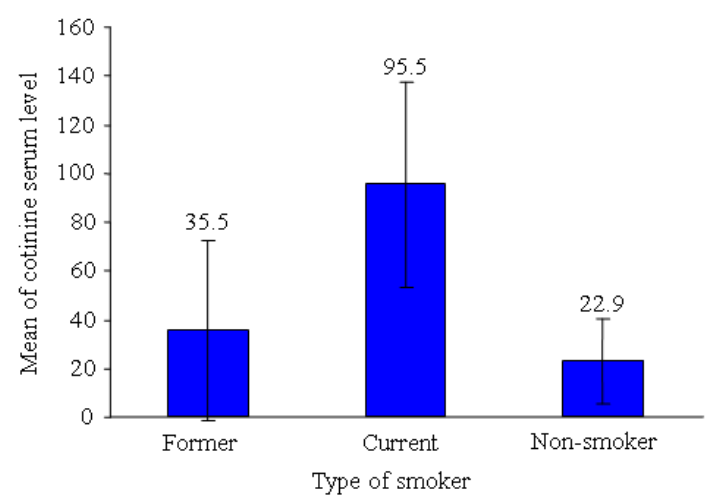

Fig. 2: Mean cotinine serum level in current smokers former smokers and non smokers

\section{DISCUSSION}

The present study was undertaken in order to evaluate the relationship between tobacco smoking and periodontal health by evaluating the serum level of cotinine in smokers, former smoker and non smokers.
The strong association found between smoking and advanced periodontal diseased is consistent with the hypothesis that smoking has cumulative detrimental effects on periodontal health (Horning et al., 1992) thus there is good evidence that the more a patient smokes the greater the degree of periodontal disease. In this study results has shown that current smokers represent a mean duration of 15 years while former smokers represent 21 years. The majority of smokers group reported consumption of $\leq 10$ cigarettes per day, while former smokers reported consumption of $\leq 10$ and $\geq 15$ cigarettes per day. It is difficult to determine the strength of smoking as a risk factor, since a problem lies in accurate measurement of a subject's exposure to tobacco products over many years and to date most studies on the relationship between smoking and periodontal diseases have determined smoking status by interview or questionnaire.

Cotinine is the principle metabolite of nicotine and as such provides a valuable quantitative measure of smoking status. Serum cotinine levels have recently been shown to correlate directly with the outcome of progressive periodontal breakdown (Machtei et al., 1997). In this study plaque index was at high level in the smoking group compared to non smokers and former smokers, however, statistical analysis revealed non significant differences. Gingival bleeding index was higher in smokers than non smokers it was more extensive in former smoker than non smokers and smokers. This was probably related in part to the less appropriate home care of the smokers. Statistical analysis showed highly significant differences. These findings were in agreement with those presented by Bergstrom (1989) and other researchers (Preber and Kant, 1973; Preber et al., 1980). The increased bleeding response to probing reported in former smokers may be related to a combination of factors including the duration of smoking habits and the amount of cigarettes consumed per day.

A better and probably the best measure of current tobacco exposure available in most studies is selfreported number of cigarettes smoked per day. Unfortunately, the utility of the finer measure will be limited to the abilities of the participants to gauge their true intake accurately (Gonzalez et al., 1996; Klesges et al., 1995). 
To get a clear idea of the effects of typical inaccuracies of self-reported smoking data on estimates of association of the clinical parameters of periodontal diseases and the smoking status, we examined the relationship between measures of clinical parameters of periodontal diseases and serum levels of cotinine. Being the major metabolite of nicotine, cotinine is an objective measure of current tobacco exposure (Hill et al., 1983). Serum is the specimen of choice for cotinine measurement since it is subjected neither to bacterial degradation nor to sample concentration.

Results of the current study indicate that serum cotinine level in smokers is much higher than that in non smoker and former smokers. Serum cotinine levels are clearly a consequence of tobacco exposure. These findings are in agreement with previous studies which concluded that cotinine can be reliably measured in blood, saliva and urine and all three sources are generally regarded as acceptable for monitoring nicotine exposure in people (Benowitz, 1983; Jarvis et al., 1988).

Several reports have found a greater association between periodontitis and systemic disease among smokers as compared to never-smokers (Hujoel et al., 2001; Hyman et al., 2002). Because periodontal disease is itself heavily influenced by cigarette usage (Tomar and Asma, 2000) and because of the imprecision of smoking data gleaned from self-report, it is difficult to remove fully the confounding effects of true tobacco exposure. We divided our smokers group into three groups according to the CIP index group healthy, with gingivitis and with periodontitis. Cotinine levels appear high in periodontally healthy patients than patients with gingivitis and periodontitis; statistical analysis revealed non-significant difference between this groups. Cotinine, the major metabolite of nicotine, is an objective measure of current tobacco exposure (Hill et al., 1983). Serum cotinine levels are clearly a consequence of tobacco exposure, the present results suggest that cotinine serum levels doesn't affected by the existence or the severity of periodontal disease.

\section{CONCLUSION}

In conclusion, the present observations clearly indicate an association between smoking, periodontal disease clinical parameters "plaque, gingival bleeding scores" and cotinine serum levels in current smokers. Cotinine serum levels doesn't affected by the existence or the severity of periodontal disease.

Due to the limited number of smokers the present results may underestimate the impact of smoking on periodontal health. Studies of larger groups are required to clarify the role of smoking in early stages of periodontal disease and the level of both serum and crevicular cotinine.

\section{ACKNOWLEDGEMENT}

The researchers express gratitude to the University of Malaya for the financial support (F 0177/2007A).

\section{REFERENCES}

Ainamo, J. and I. Bay, 1975. Problems and proposal for recording gingivitis and plaque. Int. Dent. J., 25: 229-235. PMID: 1058834

Ainamo, J., D. Barmes, G. Beagrie, T. Cutress and J. Martin et al., 1982. Development of the World Health Organization (WHO) Community Periodontal Index of Treatment Needs (CPITN). Int. Dent. J., 32: 281-291. PMID: 6958657

Barbour, S.E., K. Nakashima, S. Tangada, C.L. Hahn and J.B. Zhang et al., 1997. Tobacco and smoking: Environmental factors that modify the host response (immune system) and have an impact on periodontal health. Crit. Rev. Oral Biol., 8: 437-460. PMID: 9391754

Benowitz, N.L., 1983. The Use of Biological Fluid Samples in Assessing Tobacco Smoke Consumption. In: Measurement in the Analysis and Treatment of Smoking Behavior, Grnbowski, J. and C.S. Bell (Eds.). Government Printing Office, Washington, DC., USA., pp: 6-26.

Benowitz, N.L., F. Kuyt, P. Jacob, R.T. Jones and A.L. Osman, 1983. Cotinine disposition and effects. Clin. Pharmacol. Ther., 34: 604-611. PMID: 6627820

Bergstrom, J., 1989. Cigarette smoking as a risk factor in chronic periodontal disease. Comm. Dent. Oral Epidemiol., 17: 245-247. PMID: 2791514

Bergstrom, J., S. Eliasson and J. Dock, 2000. Exposure to tobacco smoking and periodontal health. J. Clin. Periodontol., 27: 61-68. PMID: 10674963

Cuff, M.J., M.J. McQuade, M.J. Scheidt, D.E. Sutherland and T.E. van Dyke, 1989. The presence of nicotine on root surfaces of periodontaly diseased teeth in smokers. J. Periodontol., 60: 564-569. PMID: 2681674

Garfinkel, L., 1997. Trends in cigarettes smoking in the United States. Prev. Med., 26: 447-450. PMID: 9245664

Genco, R., 1996. Current view of risk factors for periodontal diseases. J. Periodontol., 67: 1041-1049. PMID: 8910821

Gonzalez, Y.M., N. De Nardin, S.G. Grossi, E.E. Machtei and R.J. Genco et al., 1996. Serum cotinine levels, smoking and periodontal attachment loss. J. Dent. Res., 75: 796-802. PMID: 8655777 
Hill, P., N.J. Haley and E.L. Wynder, 1983. Cigarette smoking: Carboxyhemoglobine, plasma nicotine, cotinine and thiocyanate Vs self- reported smoking data and cardiovascular disease. J. Chronic Dis., 36: 439-449. PMID: 6863468

Holt, P.G., 1987. Immune and inflammatory function in cigarette smokers. Thorax, 42: 241-249. PMID: 3303428

Horning, G.M., C.L. Hatch and M.E. Cohen, 1992. Risk indicators for periodontitis in a military treatment population. J. Periodontol., 63: 297-302. PMID: 1573543

Hujoel, P.P., M.T. Drangsholt, C. Spiekerman and T.A. DeRouen, 2001. Periodontal disease and risk of coronary heart disease. J. Am. Med. Assoc., 285: 40-41. PMID: 11150099

Hyman, J.J., D.M. Winn and B.C. Reid, 2002. The role of cigarette smoking in the association between periodontal disease and coronary heart disease. J. Periodontol., 73: 988-994. PMID: 12296599

Ismail, A.I., B.A. Burt and S.A. Eklund, 1983. Epidemiologic patterns of smoking and periodontal disease in the United States. Am. Dent. Assoc., 106: 617-621. PMID: 6575080

Jarvis, M.J. M.A.H., Russell, N.L. Benowitz and C. Feyerabend, 1988. Elimination of cotinine from body fluids: Implications for non-invasive measurement of tobacco smoke exposure. Am. J. Public Health, 78: 696-698. PMID: 3369603

Johnson, I.D., D.P. Houchens, W.M. Kiuwe, D.K. Criag and G.L. Fisher, 1990. Effect of mainstream and environmental tobacco smoke on the immune system in animals and humans: A review. Crit. Rev. Toxicol., 20: 369-395. PMID: 2202327

Kenney, E.B., J.H. Kraal, S.R. Saxe and J. Jones, 1997. The effect of cigarette smoke on human oral polymorphonuclear leukocytes. J. Periodont. Res., 12: 227-234. PMID: 142132

Klesges, R.C., M. Debon and J.W. Ray, 1995. Are selfreports of smoking rate biased? Evidence from the Second National Health and Nutrition Examination Survey. J. Clin. Epidemiol., 48: 1225-1233. PMID: 7561984

Machacek, D.A. and N.S. Jiang, 1986. Quantification of cotinine in plasma and saliva by liquid chromatography. Clin. Chem., 32: 979-982. PMID: 3708822

Machtei, E.E., R. Dunford, E. Hausmann, S.G. Grossi and J. Powell et al., Cummins, 1997. Longitudinal study of prognostic factors in established periodontitis patients. J. Clin. Periodontol., 24: 102-109. PMID: 9062856
National Centre for Health Statistics, 1996. The Third National Health and Nutrition Examination Survey (NHANES III 1988-94). Reference Manual and Reports National Centre for Health Statistics, Bethesda, MD.

Pindborg, J.J., 1949. Tobacco and gingivitis; correlation between consumption of tobacco, ulceromembranous gingivitis and calculus. J. Dent. Res., 28: 460-463. PMID: 18143326

Pirkle, J.L., K.M. Flegal, J.T. Bernert, D.J. Brody and R.A. Etzel et al., 1996. Exposure of the US population to environmental tobacco smoke, the Third National Health and Nutrition Examination Survey, 1988-1991. J. Am. Med. Assoc., 275: 1233-1240. PMID: 8601954

Preber, H. and T. Kant, 1973. Effect of tobaccosmoking on the periodontal tissues of 15-year-old schoolchildren. J. Periodont. Res., 8: 278-283. PMID: 4269769

Preber, H., T. Kant and J. Bergstrom, 1980. Cigarette smoking, oral hygiene and periodontal health in Swedish army conscripts. J. Clin. Periodontol., 7: 106-113. PMID: 6929791

Raulin, L.A., J.C. McPherson, M.J. McQuade and B.S. Hanson, 1988. The effect of nicotine on the attachment of human fibroblasts to glass and human root surfaces in vitro. J. Periodontol., 59: 318-325. PMID: 3164382

Razali, M., R.M. Palmer, P. Coward and R.F. Wilson, 2005. A retrospective study of periodontal disease severity in smokers and non-smokers. Br. Dent. J., 198: 495-498.PMID: 15849588

Rivera-Hidalgo, F., 1986. Smoking and periodontal disease. A review of the literature. J. Periodontol., 57: 617-624. PMID: 3534210

Tomar, S.L. and S. Asma, 2000. Smoking-attributable periodontitis in the United States: Findings from NHANESIII, National Health and Nutrition Examination Survey. J. Periodontol., 71: 743-751. PMID: 10872955

Watts, R.R., J.J. Langone, G.J. Knight and J. Lewtas, 1990. Cotinine analytical workshop report: Consideration of analytical methods for determining cotinine in human body fluids as a measure of passive exposure to tobacco smoke. Environ. Health Perspect., 84: 173-182. PMID: 2190812 